\title{
The Role of Truth in Psychological Science
}

\author{
Jamin Asay \\ The University of Hong Kong \\ asay@hku.hk \\ Forthcoming in Theory and Psychology
}

\begin{abstract}
In a recent paper, Haig and Borsboom explore the relevance of the theory of truth for psychological science. Although they conclude that correspondence theories of truth are best suited to offer the resources for making sense of scientific practice, they leave open the possibility that other theories might accomplish those same ends. I argue that deflationary theories of truth, which deny that there is any substantive property that unifies the class of truths, makes equally good sense of scientific practice as the correspondence theory, but at lesser theoretical cost. I also argue that the considerations Haig and Borsboom draw on are better thought of as issues relevant to realism, and thus separate from the theory of truth. I conclude that while they are correct to engage questions about what makes true the various claims that arise in psychological research, they may do so without saddling themselves with a correspondence theory.
\end{abstract}

\section{Introduction}

In their recent exploration of the role for the theory of truth in understanding the nature of psychology (and science more generally), Haig and Borsboom defend the correspondence theory of truth by way of showcasing its ability to "make good sense of the many and different aspects of psychological research" (2012, p. 287). They are open to the possibility that other theories of truth—such as "deflationary" theories_might enjoy similar resources, and invite others to meet "the challenge of showing how non-correspondence theories of truth are relevant to psychology" (2012, p. 288). In this paper, I take up their challenge in the hopes of furthering our shared goal of understanding what relevance truth has for psychology. Though I do not contest their relatively modest core thesis — that "the correspondence theory of truth has the conceptual 
resources to help psychologists understand important aspects of their science" (Borsboom \& Haig, 2013, p. 812) - I believe that other theories possess these same resources, but at lesser theoretical cost. Furthermore, I maintain that some of their arguments offered in favor of correspondence theory rely on phenomena that are better understood without reference to truth at all. What I aim to accomplish in this paper is an account of how truth does and doesn't figure into some key ideas in psychological science, and what difference that makes regarding which theory of truth is correct.

I begin by articulating some of the key theories in question, and then turn to reconstructing Haig and Borsboom's various arguments in favor of correspondence theory. Then I highlight why those considerations don't depend on adopting a correspondence theory of truth. What this reveals, I believe, is that deflationary theories of truth have a more economical way of explaining the role that truth plays in science. I conclude by suggesting that some of the motivations driving Haig and Borsboom actually concern metaphysical issues like realism, such that truth itself has less relevance than might initially be thought.

\section{Lay of the land}

Haig and Borsboom's aim is to defend the correspondence theory of truth, which is widely thought to be the most commonsensical theory of truth. Although the theory is particularly vicissitudinous, having evolved in myriad ways over the last century, the core idea is straightforward (see Rasmussen (2014) for a recent thorough defense). When something like a sentence, belief, statement, or proposition (i.e., a "truth-bearer") is true, it's true in virtue of its standing in a correspondence relation to something in the world (namely, a "truthmaker"). Truth, for correspondence theorists, consists in the right kind of match obtaining between the world on the one hand, and representations of the world on the other. The task of correspondence theory is to give insightful accounts of what truth-bearers and truthmakers are, and what the nature is of the relation that stands between them.

For example, one might explicate the idea of correspondence by espousing a theory that held that sentences are true when they express propositions that are isomorphic to an existing fact. Here is an example of how this theory and its key terms might be further spelled out: the English sentence 'Snow is white', like the German sentence 'Schnee ist weiss', expresses the proposition that snow is white. This proposition is a representational device composed, in part, by the concept of snow and the concept of whiteness. The proposition's structure is isomorphic to the worldly fact of snow's being white, which itself is some sort of compound object involving snow and the property of being white. Because the structure of the proposition and the structure of the fact 
match, anything that expresses that proposition is true. Obviously, this example leaves out the details of exactly what propositions, facts, and isomorphism are (which are all contentious issues among philosophers); the challenge that philosophers sympathetic to the correspondence theory have been trying to meet for decades is giving illuminating accounts of each of these notions, and there is little consensus among them as to which accounts are best. Thankfully, these internal debates in the theory of truth are of no consequence to Haig and Borsboom's arguments, which are meant to be deployable by any particular species of correspondence theorist.

Over the course of their discussion, Haig and Borsboom mention a variety of opponents: coherentists, pragmatists, postmodernists, social constructivists, and deflationists. It's paramount to keep in mind the distinctions between these views, as Haig and Borsboom's criticisms do not apply to them equally. It's most useful, given the structure of their defense, to divide the correspondence opposition into three camps. First are the coherentists and pragmatists. These views offer what philosophers call a "substantive" theory of truth, which-like the correspondence theory-provides a philosophically robust account of the nature of truth in terms of further notions (such as coherence, consensus, utility, etc.). These accounts are "robust" in the sense that they give a theory or definition of truth that provides a unified explanation for why something is true. If $p$ and $q$ are both true, that's because they share the features that are required for truth, according to those theories. Most of Haig and Borsboom's critical remarks apply to these two theories, and I am broadly sympathetic with their overall point of view. Second are the postmodernists and social constructivists, who don't receive much attention except for a few stray remarks. I shall set them aside, as I'm unclear as to what sort of theories Haig and Borsboom have in mind, and have no present interest in defending them.

Finally there are deflationary theories of truth (e.g., Horwich (1990)). Deflationary theories of truth adopt the perspective that the various "substantive" theories-correspondence, coherence, pragmatism — rest on a mistake. To understand truth, we do not need to offer up an elaborate theory of what it takes to be true. Instead, we need only give an account of how the truth predicate 'is true' functions in language. And that predicate is best understood as a tool that enhances and enables certain expressive capacities. Here is how Haig and Borsboom define deflationism:

deflationary theories, which come in considerable variety, deny that there is a property of truth as such. Scholars who adhere to such theories argue that a substantive concept of truth is superfluous, and can be deleted from all discourse without loss of content. For deflationists, the predicate "is true" in a sentence merely performs the linguistic function 
of assenting to a proposition, and it can be dispensed with, without loss of meaning. That is, "the proposition 'general intelligence is neural plasticity' is true," for them, means exactly the same as the sentence "general intelligence is neural plasticity"; therefore, the notion of substantive truth is taken to be empty. (2012, p. 274)

This characterization of deflationism is essentially correct, though there is a danger in misinterpreting what it means to say that truth is "empty" or "superfluous", or that the property of truth doesn't exist at all. (For further discussion of what "substantive" truth comes to, see Edwards (2013) and Asay (2014).) Deflationary theses, in fact, might initially sound like some of the claims that Haig and Borsboom have in mind when they mention social constructivism and postmodernism. The best way to present the deflationary theory of truth, one which will avoid these possible misunderstandings, is to show it in action. As I shall argue later on, adopting a deflationary stance on truth is consistent with maintaining that the aim and purpose of psychology is to discover and predict the truth about minds and behavior. The fact that truth need not be defined in terms of correspondence is no barrier to its being an essential component of our understanding of science. By showing how deflationists approach the various phenomena that Haig and Borsboom consider, I hope to both illuminate what deflationary theories of truth are, and demonstrate how they are, in various ways, superior accounts of truth when it comes to understanding the role that truth plays in science.

\section{Haig and Borsboom's defense of correspondence}

Haig and Borsboom adopt the strategy of defending correspondence accounts by showing how they make good sense of psychological science. Their more modest conclusion is that correspondence theory provides adequate resources for explaining numerous important aspects in psychological science. This conclusion I do not dispute. However, they also defend a more ambitious conclusion, as when they contend that "it is essential, or at least desirable, to invoke the resources of a basic correspondence theory of truth in order to make good sense of the many and different aspects of psychological research" (2012, p. 287). My goal is to show that doing so is neither essential nor desirable. Haig and Borsboom are forthright in admitting that they haven't fully established that correspondence theories are essential, as they are open to the possibility that other theories can accomplish the same theoretical labor. By detailing how deflationists can achieve these same ends at lesser theoretical cost, I hope to show that correspondence theory is less attractive than Haig and Borsboom suggest. 
What are the aspects of psychological science that Haig and Borsboom turn to the theory of truth to explain? They assemble a broad collection of considerations, each of which, they argue, are best accounted for via correspondence:

(i) characterizing fraud,

(ii) distinguishing truth and justification,

(iii) characterizing scientific criticism,

(iv) identifying falsifiers, and

(v) distinguishing the hierarchy of claims made within psychology.

Without doubt, any theory of truth that failed to accomplish these five tasks is a failure. (Assuming, at least, that one accepts the hierarchy in (v), discussed below.) For example, any theory of truth that didn't allow for theoretical claims to be falsifiable is a non-starter. Though at times Haig and Borsboom adopt a more ambitious form of their argument- "We maintain that a presupposition of correspondence truth is essential to a proper understanding of science" (2012, p. 273, emphasis mine)-I believe they should be read as ultimately arguing that correspondence theories outperform the opposition, not that correspondence theories are the only possible game in town (e.g., "it is open to pragmatists and postmodernists to give an alternative characterization of scientific fraud without making use of the correspondence of propositions to facts. We think, however, that [...] such an account would be very difficult to substantiate" (2012, p. 281)).

Given the clarity in Haig and Borsboom's original presentation, there is no need for me to restate all the reasons they give for why correspondence theorists offer superior handlings of (i) through (v). (Many of these reasons will emerge when I discuss how the deflationist tackles them.) But here is one example that illustrates the tenor of their argument. After identifying what they call "procedural" claims in psychology (those that report on what occurred during research), they maintain that such claims are best understood as being true in the way of correspondence theory. So if a psychologist makes the claim that it's true, say, that 52 undergraduates participated in a certain experiment, then

This statement is not intended to cohere with other accepted statements, or to deliver a pragmatically useful object for use in one's belief system, but to report a fact about the research. It is a statement that reports on how a part of the world is (or was, at the time of the research), and must be read in a correspondence sense. (2012, p. 280) 
That is to say, when a researcher claims that 52 students participated in the experiment, the researcher is not making the claim that this is a useful thing to believe, or something that coheres with other things we believe (though both these claims may also be true), but that 52 students participated in the experiment. Basically, in reporting the details of what goes on during experiments, researchers are not making claims that have anything to do with us (such as facts about what's useful for us to believe or what coheres well with what we already believe), but that are directly about the world. This focus on the world outside of our minds and beliefs is what makes correspondence truth so useful to science.

Though I believe Haig and Borsboom underestimate the ability of competing theories to account for (i) through (v), I will not argue for that here. (See, e.g., Misak (1991) for a thorough defense of pragmatism.) Their critical remarks are mainly directed at coherence and pragmatist theories, and thus leave the prospects for deflationism untouched. I think that deflationary theories can achieve (i) through (v) in a simple and elegant way, and I aim to establish that in the next section.

\section{Deflationary truth and science}

As Haig and Borsboom note, there are multiple forms of deflationism about truth. Because the various intra-deflationary disputes need not concern us, I shall take the core of deflationism to be the following. First is the claim that most of our talk about truth serves a primarily expressive function. That is to say, when we introduce words like 'truth' and 'true' into our discussions, we are not introducing new content or substance into the conversation, but rather taking advantage of certain expressive conveniences. Second is the claim that there is no substantive property of truth, which must be understood in the following sense: though lots of sentences, beliefs, propositions, or what have you are true (and so in some trivial sense all possess the "property" of truth), they are not true in virtue of some single, shared feature that applies to all and only truths. Truths are true because of whatever it is they're about, not because they share some unique, identifiable property with other truths. (By contrast, consider how all samples of water are samples of water in virtue of a shared chemical structure.) This characterization of deflationism will, I hope, become clearer as I show how deflationists approach the topics broached by Haig and Borsboom.

Before addressing (i) through (v), however, let me illustrate some of the more basic features of the deflationary perspective. Suppose I assert that the first sentence of Haig and Borsboom's "Truth, Science, and Psychology" is true. Deflationists stress that what I'm doing here is indirectly asserting the same thing that Haig and Borsboom directly assert in their paper, namely, that many 
scholars have taken the idea of truth and its place in life to be of major importance (2012, p. 272). (Truth is thus "disquotational": if ' $p$ ' is true I can infer that $p$.) Similarly, suppose I remark to a friend "Your birthday is coming up next week" and she responds "That's true". Here she expresses agreement with my assertion because her expression, by way of 'true', carries the same content as mine. We have both made the same claim, namely, that her birthday is coming up next week, though we used different words to do so. She could have expressed agreement with me by saying "My birthday is coming up next week", but the presence of 'true' in our language gives us a simpler and less redundant way of doing so. This is an example of what I mean by saying that 'true' offers expressive conveniences, and does not introduce new content.

The expressive functions of 'true' are in some cases not just convenient, but indispensable, practically speaking. Suppose I believe some, but not necessarily all of Pinker's claims in The Language Instinct (1994). I can express my assessment by saying "At least one sentence in The Language Instinct is true". How would I express myself without using 'true' (or any of its synonyms)? I would need to express each claim in The Language Instinct as a giant disjunction:

Either Pinker has never met a person who is not interested in language, or Pinker wrote The Language Instinct to try to satisfy that curiosity, or language is beginning to submit to that uniquely satisfying kind of understanding that we call science, but the news has been kept a secret, or...

Doing so, of course, is incredibly tedious and time-consuming. Hence, having a truth predicate around is of enormous expressive utility.

One way to understand the deflationary thesis is that expressions involving truth are not independently meaningful — they are anaphora that inherit their meaning from the things to which truth is ascribed (much as how the meaning of pronouns is parasitic on antecedent noun phrases). To know the meaning of 'What Charlie said is true', we need to know what Charlie said. Likewise, for deflationists, sentences that employ 'true' don't "add" any content on top of that to which truth is being ascribed: 'It's true that Wundt was German', 'Wundt was German' is true', and 'Wundt was German' all, more or less, say the same thing. If that is the case, then the deflationists' denial that different truths enjoy their truth in virtue of a single shared property becomes quite plausible. If the sentence 'Infants do not develop object permanence before eight months of age' is true, it's true because infants do not develop object permanence before eight months of age. If the sentence 'Humans possess an innate, genetically determined faculty for language' is true, it's true because humans possess an innate, genetically determined faculty for language. Most 
deflationists concede that there is a very weak sense in which these two sentences "share" the property of truth: they're both true (e.g., Horwich, 1990, p. 38). But the sense in which these two sentences "share the property of truth" is quite different from how substantivists see the matter, and quite different from how they share other genuine properties, such as being in English and being examples in an academic paper.

\subsection{Fraud}

I now make the case for why deflationists can handle Haig and Borsboom's five desiderata without difficulty. First is the characterization of fraud. They understand accusations of fraud as the "denial of correspondence truth at the procedural or data level" (2012, p. 286). The procedural and data levels to which they refer are, in effect, the claims relevant to science that report on the basic goings-on of experiments and the data collected. (These are distinguished from more theoretically-loaded generalizations, causal claims, explanatory hypotheses, and others.) Examples of procedural- and data-level claims are, respectively, 'The experiment subjected 50 cotton-top tamarins to stimulus $s$ ' and ' $80 \%$ of the cotton-top tamarins subjected to stimulus $s$ exhibited behavior pattern $p$ '. Claims of fraud are directed only at claims such as these, as it's inappropriate, for example, to charge someone with fraud only for offering an explanation of the data with which one disagrees. Reasonable minds might disagree on the causal explanation for some observed regularity; reporting the facts incorrectly regarding the raw data, however, introduces the possibility of fraud.

The deflationist's account of fraud maintains that the theory of truth, in this instance, is idle. That is to say, we can account for what fraud consists in without talking about truth at all. (Or, if we do use truth to define fraud, we're just using truth for its usual expressive convenience.) Suppose I accuse Professor Cheat of fraud with respect to the following sentence from his published study: ' $80 \%$ of the cotton-top tamarins in the study exhibited behavior pattern $p$ following stimulus $s^{\prime}$. What I'm doing is claiming that Professor Cheat is, with intention to deceive, asserting that $80 \%$ of the cotton-top tamarins in the study exhibited behavior pattern $p$ following stimulus $s$ when he knows full well that it's not the case that $80 \%$ of the cotton-top tamarins in the study exhibited behavior pattern $p$ following stimulus $s$. We could describe Cheat's behavior in terms of truth: he commits fraud by knowingly presenting a falsehood regarding his data and methods as truth. But in so doing, we're just saying that he asserts that $p$ when he knows that not$p$. Hence, we don't need to bring in talk of correspondence truth to understand what fraud is, as Haig 
and Borsboom do. Truth alone suffices, and truth itself in this instance is just an abbreviation for the content of the actual claims at issue.

\subsection{Justification}

Next we come to the distinction between justification and truth. As Haig and Borsboom point out, distinguishing these two concepts is paramount in science. One need only look to the history of science to find ample grounds for distinguishing the two. For example, Newton was well justified in his beliefs in his physical theories, though we now know them to be false.

The deflationist has no difficulty in accounting for the distinction between truth and justification. What it is for 'Infants do not develop object permanence before eight months of age' to be true is for infants not to develop object permanence before eight months of age; what it is to be justified in believing the sentence is to have good grounds and reasons for believing that infants do not develop object permanence before eight months of age. Furthermore, it's possible that one could have good reason for believing that infants do not develop object permanence before eight months of age, even if infants do develop object permanence before eight months of age- the evidence might have been misleading or misinterpreted, for instance. For the deflationist, what we mean when we say that justification and truth are distinct is that one could have good reason for believing that $p$ even though it's not the case that $p$. Again, the notion of correspondence need not be invoked.

\subsection{Scientific criticism}

Next we come to the need to characterize the nature of scientific criticism. Once again, Haig and Borsboom argue that correspondence truth enables us to understand what goes on during scientific criticism. They imagine an example in which a researcher objects to a claim you made in a paper:

your colleague, Professor Brainsweat thinks that your explanation is flawed and writes a paper expressing his criticisms. In particular, he questions an assumption, $A$, that you made, say, that the property in question arose in response to certain environmental pressures that shaped selection. Brainsweat thinks that these environmental pressures did not exist, and he writes a critical commentary on your paper to argue his point. (2012, p. 279) 
What we have here is disagreement over whether or not certain environmental pressures existed at a certain time and place. Haig and Borsboom sensibly point out that Brainsweat's fundamental goal in presenting his objections is not to doubt whether the existence of such pressures coheres with someone's worldview, or whether future scientists will come to a consensus on their existence. What he is doing, they say, is claiming "that the environmental pressures mentioned in $A$ did not exist so that there are no facts to function as truthmakers for your potential truthbearer $A$ "' (2012, p. 279; cf. Borsboom and Haig, 2013, p. 814).

I believe, however, that Haig and Borsboom are still overanalyzing Brainsweat's action. In claiming that the environmental pressures under dispute did not exist, he's claiming that they did not exist: no more, and no less. Brainsweat might accept the implication that, therefore, there are no facts to serve as truthmakers for the claim made in the original paper-but only if Brainsweat is a committed correspondence theorist, which is no part of the setup to the hypothetical example. When Brainsweat asserts that assumption $A$ is false, he's asserting that it's not the case that the property in question arose due to the environmental pressures; he thinks it's false that those pressures existed, and so they can't have caused anything. Haig and Borsboom are correct to maintain that Brainsweat is objecting to the existence of the pressures themselves, and not anything to do with the belief systems of current and future researchers. But that is precisely what the deflationist would say about the case. When Brainsweat claims that the sentence 'Certain environmental pressures caused the appearance of certain properties in human beings' is false, he's denying that certain environmental pressures caused the appearance of certain properties in human beings. When we criticize someone's claim as not being true, we are criticizing the claim itself, and not tangential claims about various systems of belief. That insight, I believe, is what Haig and Borsboom are hoping to express. It's an insight, however, that is best explained by deflationism. When we challenge the truth of each other's assertions, we are challenging the assertions themselves, not some property they may or may not have.

\subsection{Falsifiers}

The fourth feature of scientific practice of interest to Haig and Borsboom is the identification of falsifiers. It's crucial, in doing respectable science, to think about not only what would confirm the truth of a theory, but also what would serve to falsify it. Correspondence truth, they claim, makes sense of this feature of science: 
a correspondence reading of propositions makes clear not only what the researcher is assuming, but also what possible refuting material would look like. That is, a correspondence reading of theories immediately generates possible falsifiers for the theory. This is an important function in scientific discourse that, ironically, theories about discourse, such as postmodernism, cannot explain, because they typically deny any function for correspondence. (2012, p. 279)

Haig and Borsboom may be correct that postmodernists cannot make sense of falsification, but I disagree with the implication that commitment to correspondence is necessary for articulating possible falsifiers. To see what falsifies a claim, we don't need to give a "correspondence reading" of it; we just need to read it.

Suppose a Chomskian defends the claim that all humans possess the ability to learn languages with recursion. This claim is a universal generalization, which means that it applies a property (possession of the ability to learn languages with recursion) to each member of the specified set (humans). To falsify the claim, one simply needs to identify a human being who does not possess the ability to learn a language with recursion. If a developmental psychologist claims that no infant develops object permanence before eight months of age, then the kind of counterexample needed is immediately apparent: produce an infant with object permanence who is younger than eight months old, and the claim has been falsified. These cases are quite simple. It's less clear how to falsify, say, the claim that smoking causes lung cancer. Smoking does cause lung cancer, but this claim is not refuted by the existence of individual smokers who happen not to develop lung cancer. The conclusion to draw from this example is only that 'Smoking causes lung cancer' does not mean the same thing as 'Everyone who smokes develops lung cancer'. The meaning of the latter claim is straightforward, and easily falsified. The former is not so straightforward, which is why there is enormous dispute within the philosophy of science as to how to interpret causal claims. Such disputes, however, are not settled by adopting a correspondence theory of truth. They're settled by articulating and defending a theory about the nature of causation. So again, the theory of truth doesn't have any obvious role to play in generating falsifiers for theories. As long as we understand the meaning of those theories, we can identify what sorts of observations would entail their falsity. We need to attend to the content of the claims themselves to discover what would falsify them, and attending to the content of the claims themselves is exactly what deflationists think we're doing when we evaluate the truth and falsity of our utterances. 


\subsection{Hierarchy}

Finally we come to the hierarchy of claims made within psychological science. Haig and Borsboom present the claims made by psychological science as belonging to a four-tiered hierarchy. First come procedural claims, which are basic reports of what goes on in research: that 50 cotton-top tamarins were exposed to stimulus $s$, say. Second is the data level, acceptance of which involves not the interpretation of the data, "but merely the acceptance of the data themselves" (2012, p. 281). When psychologists assert that $80 \%$ of those cotton-top tamarins behaved in a certain way in response to the given stimulus, they are making a claim that belongs to the data level. The third level, the phenomenal, introduces theoretical interpretations and/or extrapolations of the data. For example, the researchers might claim that $80 \%$ of the broader population of cotton-top tamarins would respond in a certain way were they provided the relevant stimulus. Finally there is the causal level, where claims are made regarding the causes of the phenomena expressed at the previous level. For instance, perhaps it is a certain kind of intelligence in the tamarins that causes them to behave as they do.

Haig and Borsboom make a number of useful and interesting observations regarding the hierarchy. For one, they use it to differentiate between fraud and other forms of criticism. When Professor Cheat says something I take to be false at the phenomenal or causal levels, it would be inappropriate to charge him with fraud. He may have insufficient data to support his ampliative inferences, or may have put forward an implausible explanation of his results. He might be a poor reasoner or a bad theorist, but he is not yet a fraud. But if Cheat puts forward false claims at the procedural or data level, he's guilty of fraud (if he acts with the intention to deceive) or negligence (if his falsehoods are unintentional). Secondly, Haig and Borsboom go into some detail regarding how the claims at different levels of the hierarchy may have substantially different truthmakers. For example, unobservable entities and processes might be posited in order to make true various causal claims, whereas the truthmakers for procedural-level claims might just involve readily observable empirical events and states of affairs.

I take no stand as to whether Haig and Boorsboom's hierarchy is ultimately the best way of organizing the structure of psychological theories. Their only claim about the hierarchy that is pertinent to my aim is their contention that "the correspondence theory is much more useful than any of its competitors [...] in outlining the hierarchical and complex structure of facts presumed in high-level causal theories" (2012, p. 287). In response, first I would point out that my own presentation of the hierarchy was done entirely without reference to truth, let alone correspondence truth. One can divide the claims of psychological science into the four categories 
without supposing that the different claims enjoy different kinds of correspondence. What separates the various claims are their content—what they are about.

But there is something else that Haig and Borsboom wish to account for, and that is how the truthmakers for the claims seem to probe deeper and deeper into the structure of the world as we climb the hierarchy. For instance, the procedural level "makes no serious claims about a basic structure of reality" (2012, p. 280), whereas phenomenal claims can make "an ontological commitment to the structure of the world" (2012, p. 283), and causal claims even make commitments to how the world would have been had certain counterfactual conditions obtained. I take it that Haig and Borsboom see it as a virtue of their account that as the truths of psychological science ascend the hierarchy, so too does the complexity of their truthmakers. To this I reply that the deflationist about truth need not dispute anything that Haig and Borsboom claim regarding the different kinds of truthmakers for different kinds of scientific claims. It's no surprise that as researchers make claims about deeper and more fundamental levels of reality, their claims are in turn made true by deeper and more fundamental parts of reality. After all, that reality is what those claims are about.

Now, this reply might seem unavailable. How can the deflationist agree with the correspondence theorist as to what makes these various claims true? How can deflationists talk about truthmaking at all? This worry, it seems to me, rests on a misunderstanding of the deflationary theory of truth. (And one which, I believe, even some deflationists harbor.) It's no thesis of deflationism that truths don't have truthmakers. Deflationists need not deny that when something is true, it's true in virtue of what's going on in the world. Take the sentence 'Obama exists'. A deflationist would point out that 'Obama exists' is true because Obama exists. Had Obama not existed, the sentence 'Obama exists' wouldn't have been true. But to concede this simple point is not in and of itself to adopt a correspondence theory of truth, and its commitment to a complex theory of correspondence relations, facts, and the like. Deflationists deny that we need a robust commitment to a substantive property of truth to provide a uniform explanation as to why 'Obama exists' and all other truths are true. A deflationist should say that the right ontological commitment involved in accepting the truth of 'Obama exists' is just to Obama himself, and not to a correspondence relation or set of entities called 'facts'. David Lewis, for instance, argues that "the Truthmaker Principle coexists peacefully with the deflationary conception of truth" (2001b, p. 605), and argues quite forcefully against correspondence theories (2001a). When it comes to, say, the proposition that there is a cat, Lewis observes: "It is true because it has a truthmaker. And what are its truthmakers? Cats. So it is true because there is a cat" (2003, pp. 28-29). 
Employing the language of truthmaking is not in and of itself to adopt the correspondence theory of truth. As I see things, the correspondence theory (like the other substantive theories) offers its theory of truth by way of offering a theory of truthmakers. Correspondence theorists look to "worldly facts", whereas coherence theorists turn to relations between propositions, and pragmatists look to the beliefs of future researchers within an ideal "final" science. Deflationists, by contrast, stay silent on the matter. A deflationist doesn't tell you what makes a claim true, at least beyond the near-trivial claim that it's true that $p$ because $p$. It's not up to the truth theorists, as it were, to tell you what the truthmakers are for claims about psychological science-that's the task of psychologists (perhaps in tandem with philosophers of psychology). Likewise, it's not the job of truth theorists to give accounts of what makes theories in physics or chemistry true; that should be left to physicists and chemists. From a deflationary point of view, the story about truth is very simple. Any claim that $p$ is true if and only if $p$. But the story of what makes those truths true is an elaborate one that involves digging into whatever science it is that is tasked with discovering and understanding them (cf. Simons, 1992, p. 175).

\section{Truth and realism}

At one point in their discussion, Haig and Borsboom note the connection between their interest in the correspondence theory of truth and scientific realism:

it should be noted that correspondence truth and metaphysical realism are natural allies, for facts are naturally understood as mind-independent parts of reality, and it is facts that make truthbearers' correspondence true. We ourselves subscribe both to correspondence truth and metaphysical realism and, furthermore, we take these as two aspects of our broader commitment to scientific realism, which is the philosophy of science we presuppose in the following discussion of truth and scientific practice. (2012, p. 279)

One way to interpret my remarks on the deflationary theory of truth is that it reveals that the work that needs to be done to make sense of the practice of psychological science is actually being performed by Haig and Borsboom's commitment to realism, not their commitment to correspondence. The basic idea behind realism is that the world —or much of it, anyway-exists independently of the way we think about it. It's true that bonobos would have had the capacity to communicate with signs, even if we had never discovered that fact about them. It would be true even had we (wrongly) believed otherwise. For realists, there can be facts regarding matters for 
which we will never have any evidence, and that we may not have ever even contemplated. For example, I presume that (until just now) no one has ever entertained the question as to how many dinosaurs slept more than eight and a half hours during the 24 hour period beginning exactly 68 million years prior to 11:25 p.m. Greenwich Mean Time, October 24, 2016. Presumably, there is a fact of the matter as to how many there were, though of course no one could ever find out. (Those equipped with time machines would hopefully dedicate their resources to more pressing matters.) My contention is that realism plays a much larger role in understanding the practice of science as understood by Haig and Borsboom than does correspondence. Thus, the reason deflationists have no trouble meeting the desiderata laid out by Haig and Borsboom is that deflationism is no barrier to realism, which is a point they acknowledge (2012, p. 278).

That Haig and Borsboom's true interest lies in realism surfaces, for example, when they write: "This underscores exactly the point of correspondence truth: the truthmaker is a relevant part of the world, rather than of the researcher" (2012, p. 281). It's the nature of the truthmaker that matters - not how that truthmaker may or may not fit into some theory of truth. The sort of view that Haig and Borsboom recommend against is one that sets aside "the world" and focuses instead on the researcher. What they rightly contest is that the truths discovered by science are made true by matters that are fundamentally dependent upon the minds, beliefs, and judgments of researchers. One way to think about coherence and pragmatic theories of truth is that they locate the truthmakers of truth with the mind-dependent. For coherentism, the truth of your beliefs is a function of what other beliefs you have. For pragmatism, the truth of your beliefs is a function of what's useful for you, or of what other people will believe at some future stage of scientific inquiry. What drives Haig and Borsboom's criticisms of these non-correspondence theories of truth, I believe, is this background mind-independent metaphysical view that they employ. What science aims to discover, on their view, is the truth about an objective, shared world that exists largely independently of the minds that think about it, and that task is harder to square with a coherence and pragmatic theories of truth.

What I would contend-and I believe Haig and Borsboom would concur-is that most psychological science (and most science, period) operates against a backdrop of metaphysical realism. There is a world that exists as it does largely independent of us and our interests, and that is fruitfully studied and explored by empirical scientific methods. I believe that their concern to defend the correspondence theory of truth largely relies on their intent to defend the role of this metaphysical picture in science. However, I do not think that advocating correspondence is the right response, and I shall close with a few remarks that begin to say why. 
First, to embrace the correspondence theory of truth is not yet to embrace a realist metaphysical worldview. Haig and Borsboom make this point themselves, when they note that "At some strain, one could be a correspondence theorist and an idealist, as was J. E. M. McTaggart" (2012, p. 278). What this admission reveals is that one could adopt a correspondence theory of truth, but go on to maintain that the corresponding objects are all mind-dependent entities. (Think of Berkeley's (1998) infamous worldview that reality is exhausted by minds and their ideas; the very idea of mind-independent matter, he argued, was incoherent.) As I would put the point, the longstanding friendship between correspondence theories of truth and metaphysical realism is sociological, not logical. There is no logical guarantee that with correspondence comes realism, though traditionally, as a matter of contingent fact, these theories have been defended hand in hand. So if it's realism that one is after, there's no logical compulsion to be a correspondence theorist.

Second, because deflationism can be paired with realism just as well as correspondence can, Haig and Borsboom's five desiderata actually point toward the former, which offers a theoretically simpler account of truth. This paper is not the place to offer a comprehensive account of the advantages of deflationism over correspondence (for that see Horwich (1990)), but a few points are worth mentioning. First, by taking on a correspondence theory of truth, one immediately commits to there being a truthmaker for every truth. If truth is constituted by the having of a truthmaker, then it's impossible for there to be truths with no truthmaker. However, there is considerable dispute over whether all truths have or need truthmakers (see, e.g., Lewis (2001)). In his critical discussion of Haig and Borsboom, Markus (2013) lands on a few of the familiar problem areas, such as the case of logical truths. Does there need to be something in the world that makes it true that two plus two is four? One might think otherwise. Or consider 'Psychology is the science of mind and behavior'. Such "truths by definition" might be thought not to owe their truth to what's going on in the world, as do, say, contingent claims such as 'B. F. Skinner practiced psychology'. That sentence couldn't have been true without reality being a particular way, and including certain entities (namely, Skinner himself). It makes little sense, by contrast, to speak of the world being such that psychology wasn't the science of mind and behavior. There might never have been psychologists, and the word 'psychology' might have ended up meaning something entirely different, but those are separate matters. Other examples include "negative existentials" such as 'There are no speaking apes' (or, equivalently, 'All apes are non-speaking'). Even if there are facts to make it individually true of each ape that he or she doesn't speak, we would need some further "and those are all the apes" fact to support the general claim, but it's unclear what such a thing would be. (See Molnar (2000) for a discussion of this issue.) 
To say that deflationism enjoys a number of advantages over correspondence theory is not to say, of course, that deflationism has no problems of its own. Some uses of 'true', for instance, are not amenable to standard deflationist analyses. The sentence 'To assert a proposition is to present it as true', for example, uses 'true' in a way such that it cannot be removed without loss (Simmons, 2006, 203). Others have argued that once truth is deflated, its connection to other important concepts like linguistic meaning are lost (e.g., Bar-On, Horwich, and Lycan (2001)). (For a number of other objections to deflationism, see the thoroughgoing critical accounts offered in David (1994) and Künne (2003).) Note, however, that these criticisms of deflationism don't have any obvious bearing on the matters of interest to Haig and Borsboom. So these objections don't reveal that deflationism is any less capable of accounting for the practice of psychological science than is correspondence theory. Hence, even if deflationism has problems of its own, it's still a more desirable theory of truth for psychology than correspondence. (Ultimately, I recommend a theory of truth that avoids the excesses of both correspondence and full-throttle deflationism; see Asay (2013a).)

I commend Haig and Borsboom for their recognition of the importance of thinking about what makes true the various kinds of claims made within psychological science. Their approach to their hierarchy is laudable, at least insofar as it encourages theorists to think about what sorts of ontological posits are needed to ground the different sorts of truths that are asserted in the course of scientific research. Their observation that very different truths in psychology require very different truthmakers is an important one, and one that I believe is a more natural fit with a deflationary theory of truth. Again, the deflationary perspective is that truths themselves aren't all that uniform - they don't admit of a uniform explanation, as is required by correspondence theories. Individual truths are concerned with their own individual subject matter, and what truthmaker they have (if any) is a matter that must be decided on a case-by-case basis. Haig and Borsboom's instinct to seek after the ontological grounds (i.e., truthmakers) of psychological theories is the right one, though there are advantages to divorcing it from the correspondence theory of truth.

\section{Conclusion}

At the end of the day, in some respects my proposal isn't all that different in substance from Haig and Borsboom's. They pair their commitment to realism with a correspondence theory of truth (that employs "realist" truthmakers), whereas I am suggesting, on their behalf, a commitment to realism (in the form of objective, judgment-independent truthmakers) paired with 
a deflationary theory of truth. Ontologically speaking, the two views will largely agree; that is to say, they may share a similar worldview, in terms of what exists, and what the structure of the world is like. (They will likely differ when it comes to certain details; for example, the correspondence theorist may need to posit additional entities to make true definitional and negative truths.) But I think the deflationist has the proper understanding of what role truth plays in that worldview. Science aims at discovering objective truth - that is something to which Haig and Borsboom and I can agree. However, that does not mean that there has to be a substantive property of truth that unifies the class of truths, as the correspondence theory maintains. Deflationism stresses that we don't need to worry about a special property truth, we just need to concern ourselves with individual truths.

As for Haig and Borsboom's commitment to realism, a parallel question arises: does psychology really need a commitment to realism, or would a more modest philosophy of science suffice? This paper is not the place to take up that matter in full, but it's worth noting that there are philosophers who argue that science can get by with less than full-blown realism, just as I've argued it can get by with less than correspondence: Bas van Fraassen's constructive empiricism (1980) and Arthur Fine's "natural ontological attitude" (1984) are two prominent examples. I am highly critical of these approaches to the topic of scientific realism (see Asay (2013b)), but they do offer alternatives to scientific realism that do not go down the road of postmodernism and social constructivism that Haig and Borsboom are keen to reject. I invite Haig and Borsboom, as well as those who share their general outlook, to consider whether one of these alternative perspectives might also provide an adequate metaphysical basis for psychological theorizing.

\section{Acknowledgments}

My thanks go to the referees for the journal for their valuable feedback. The research in this paper was supported by a grant from the Research Grants Council of the Hong Kong Special Administrative Region, China (HKU 23400014).

\section{References}

Asay, J. (2013a). The primitivist theory of truth. Cambridge: Cambridge University Press.

Asay, J. (2013b). Three paradigms of scientific realism: a truthmaking account. International Studies in the Philosophy of Science, 27, 1-21.

Asay, J. (2014). Against truth. Erkenntnis, 79, 147-164. 
Bar-On, D., Horisk, C., \& Lycan, W. G. (2000). Deflationism, meaning and truth-conditions. Philosophical Studies, 101, 1-28.

Berkeley, G. (1998). Three dialogues between Hylas and Philonous (J. Dancy, Ed.). Oxford: Oxford University Press.

Borsboom, D., \& Haig, B. D. (2013). In defense of correspondence truth: a reply to Markus. Theory and Psychology, 23, 812-818.

David, M. (1994). Correspondence and disquotation: an essay on the nature of truth. Oxford: Oxford University Press.

Edwards, D. (2013). Truth as a substantive property. Australasian Journal of Philosophy, 91, 279-294.

Fine, A. (1984). The natural ontological attitude. In J. Leplin (Ed.), Scientific realism (pp. 83-107). Berkeley: University of California Press.

Haig, B. D., \& Borsboom, D. (2012). Truth, science, and psychology. Theory and Psychology, 22, $272-$ 289.

Horwich, P. (1990). Truth. Oxford: Basil Blackwell.

Künne, W. (2003). Conceptions of truth. Oxford: Clarendon Press.

Lewis, D. (2001a). Forget about the 'correspondence theory of truth'. Analysis, 61, 275-280.

Lewis, D. (2001b). Truthmaking and difference-making. Nồs, 35, 602-615.

Lewis, D. (2003). Things qua truthmakers. In H. Lillehammer \& G. Rodriguez-Pereyra (Eds.), Real metaphysics: essays in honour of D. H. Mellor (pp. 25-42). London: Routledge.

Markus, K. A. (2013). Correspondence without correspondence theory: comment on Haig and Borsboom. Theory and Psychology, 23, 806-811.

Misak, C. J. (1991). Truth and the end of inquiry: a Peircean account of truth. Oxford: Clarendon Press.

Molnar, G. (2000). Truthmakers for negative truths. Australasian Journal of Philosophy, 78, 72-86.

Pinker, S. (1994). The language instinct: the new science of language and mind. New York: Harper Collins.

Rasmussen, J. (2014). Defending the correspondence theory of truth. Cambridge: Cambridge University Press.

Simmons, K. (2006). Deflationism and the autonomy of truth. Philosophy and Phenomenological Research, 72, 196-204.

Simons, P. (1992). Logical atomism and its ontological refinement: a defense. In K. Mulligan (Ed.), Language, truth and ontology (pp. 157-179). Dordrecht: Kluwer Academic Publishers.

van Fraassen, B. C. (1980). The scientific image. Oxford: Clarendon Press. 